layout, clarity, accuracy, and relevance were all rated high; and a vast majority (85\%) considered the GBR "highly valuable" for prioritising, developing, and monitoring burn prevention programs.

Conclusions The GBR was shown to be simple, flexible, and acceptable to users. Enhanced regional and global understanding of burn epidemiology may help prioritise the selection, development, and testing of primary prevention interventions for burns in resource-limited settings.

\section{WHAT INFLUENCES PARENTS OF CHILDREN UNDER 5 YEARS OF AGE TO TAKE SAFETY MEASURES}

Eva van Zoonen, Rob Baardse. Dutch Burns Foundation, The Netherlands

\subsection{6/injuryprev-2016-042156.103}

Background Children under 5 years of age are at high risk for sustaining burn injuries. In the Netherlands, $26.8 \%$ of the patients with burn injuries who require admission to a burn centre, are under 5 years of age. Most burns in children under 5 years of age are scalds. The majority of scalds can be prevented when appropriate measures are applied. To apply these measures, parents must know about the risks of scalding, the ability to perform precautionary measures and parents must be willing to perform these measures. The aim of this study was to identify the underlying determinants that influence the desired behaviour Methods Parents of children under 5 years of age, recruited by a Facebook advertisement, completed an internet survey. The questions in the survey described 9 measures, that are effective to prevent the most common causes of scalds. The parents were first asked whether they performed the particular safety measure, after which an explanation of the safety measure was given followed by a question about the parents motivation to perform/not perform this measure. Knowledge and attitude were measured by using a multiple choice question. Other determinants of behaviour were examined by an open-ended question.

Results One of the important outcomes of the survey was that parents think that it is important for a young child to learn to cope with dangerous situations and thereby overestimate the cognitive capacities of children. In addition, parents think that their child is too small to be in danger and do not take into account their sudden development of physical skills. Furthermore, parents overestimate their own ability to keep a constant eye on their child.

Conclusions In order to develop effective prevention interventions, it is necessary to gain insight into the motivation of parents to perform safe or unsafe behaviour formed by the determinants of behaviour. Our outcomes provide a theoretical base for future prevention strategies aimed at the prevention of burn injuries in children.

\section{PARENTS' RISK PERCEPTION ABOUT CHILDRENS' INJURIES AND BURNS: A MULTIDIMENSIONAL UNFOLDING TECHNIQUE}

\footnotetext{
${ }^{1}$ Veronica Diaz, ${ }^{2}$ Frank Busing, ${ }^{1}$ Maria Orozco, ${ }^{1}$ Alfredo Celis, ${ }^{3}$ Ariel Miranda, ${ }^{1}$ Patricia Mendoza. 'University of Guadalajara, Mexico; ${ }^{2}$ Leiden University, The Netherlands; ${ }^{3}$ Hospital "Dr. Juan I. Menchaca", Mexico
}

10.1136/injuryprev-2016-042156.104
Background Unintentional injuries are a significant issue of public health, accounting $60 \%$ of infant mortality around the globe. In Mexico, burns are the most frequent injury at home. This research explores parents risk perceptions about children's injuries and burns.

Methods Multidimensional unfolding is a technique that maps ranking data into a low-multidimensional space that allows for a visual comprehension of the data. 28 parents of Guadalajara, Mexico (15 mothers, 13 fathers), were asked to sort three series of cards (adverse events, agents that could cause a burn, and people who take care of a child) by two different criteria: probability and severity. The last series was sorted only by probability.

Results The five perceptual maps have two dimensions, which show two sets of objects each: the subjects (the sample of 28 parents) as numbers, and the objects (either adverse events, agents that could cause a burn or people who take care of a child) as labels. The closer a number is to a label, the more probable or severe the label is considered by that number. Unfolding also permits for sub-dimensions or clusters in the configuration. Parents perceived as more probable to happen: fall, choking, and cut. They did not considered cut and fall as severe. Sun, hot liquids, and hot objects were the most probable agents. None perceived sun, ice, hot objects, smoke, and steam as severe agents. Mother and father were considered the least probable to experience a children's injury.

Conclusions Multidimensional unfolding is an exploratory technique; ideal for research for the first time in Mexico, parents perceived risks or not. For example, smoke was perceived as not probable to cause a burn and ignore as severe. According to the World Health Organisation, burns include the respiratory damage resulting from smoke, being the most frequent cause of death. Parents were omitting important information. This is only the first step, is essential further investigation in this area.

\section{FAST AND AGILE FIRE EXTINGUISHING METHODS FOR FIRE \& RESCUE FIRST RESPONSE}

${ }^{1}$ Marko Hassinen, ${ }^{2}$ Arto Latvala. ' Emergency Services College, Finland; ${ }^{2}$ Keski-Uusimaa Fire and Rescue Services, Finland

\subsection{6/injuryprev-2016-042156.105}

Background New agile fire extinguishing methods could be used instead of, or in combination with, traditional fire hose method in a number of situations, such as small fires in large buildings (Hospitals, Shopping malls), where the traditional fire hose method is rather slow.

In rural areas the first unit to respond is often a command unit that has neither the crew nor the equipment to carry out the traditional fire hose extinguishing. Provisioning fast and lightweight units with agile and lightweight fire extinguishing methods would speed up the process of getting the help. The improvement in the countryside service level would be obvious. Methods We surveyed and evaluated new, innovative fire extinguishing methods in order to find out if they are useful as complementary methods. Sometimes these new methods are sufficient as such, but most often best used in combination with the traditional fire hose.

We investigated the usefulness of these methods through standardised burn experiments as well as field tests in actual house fires.

The test setup was based on research of most common causes and sources of house fires based on the statistical data. A comparison was also carried out also from the performance perspective, 
not overlooking work safety issues. All the experiments were be carefully documented using video and thermal imaging.

Results The tests revealed both the usefulness of agile extinguishing methods and their limitations. Also, several best practices for different extinguishing methods were defined. The new, agile extinguishing methods can clearly improve Fire \& Rescue response as the actual scene can be reached much faster than in the past.

Conclusions Fire \& Rescue services can improve their level of service by a choice of extinguishing method. This will also affect the extent of damage to both victims of an incident as well as buildings and other material.

\section{RESEARCHING CHILDREN'S EXPERIENCE OF TRAUMATIC EVENTS; EXPLORING CHILD BEHAVIOUR IN DWELLING FIRES}

Julie Mytton, Trudy Goodenough, Claire Novak, Jane Hughes, Julie Woodley. University of the West of England, Bristol, UK

\subsection{6/injuryprev-2016-042156.106}

Background Understanding child behaviour during injury-risk events supports development of injury prevention education and interventions, but asking children to recall events may cause distress. We found an absence of published evidence on childreported behaviour in accidental dwelling fires. Therefore we aimed to develop methods to; identify and recruit families who had an accidental fire at home; enable families to tell their stories with minimal distress, and test the feasibility of such methods for a future study.

Methods Consultation with frontline, educational and strategic staff in the Devon and Somerset Fire and Rescue Service (DSFRS), parents, young people, the mother of a burned child and working with a clinical psychologist and ethics committee Chair informed the development of methods for family identification, recruitment and participation. The DSFRS identified dwelling fires in the previous 12 months and sent study information inviting families to contact the research team.

Results Leaflets sent to 218 households resulted in 8 enquiries (3.7\% response) and 3 families recruited (1.4\% participation). Families were more likely to engage if contacted 3-6 months after the fire than if $>6$ months. Five parents and 6 children took part. Face-to-face interviews included a meeting with the parents alone to learn about the fire and negotiate arrangements for the children's interview, conducted later that day, led by a psychology researcher. Art materials enabled children's storytelling and strategies provided to stop the interview if children became distressed. Support for families and researchers after the interviews was required.

Conclusions Engaging families in qualitative studies of potentially distressing injury-risk events requires extensive preparation, flexibility and negotiation. Examples of materials and learning from this study will be presented and may be applicable to other injury research studies where hearing the voice of the child is paramount.

\section{DIFFERENCES IN DETERMINANTS AMONGST INDIVIDUALS REPORTING RESIDENTIAL FIRES IN SWEDEN- RESULTS FROM A CROSS-SECTIONAL STUDY}

Finn Nilson, Carl Bonander, Anders Jonsson. Division of Risk Management, Department of Environmental and Life Sciences, Karlstad University, Karlstad, Sweden

\subsection{6/injuryprev-2016-042156.107}

Background Whilst determinants for fire mortality and morbidity are well documented, the determinants of residential fires, regardless of outcome, are less known. This study aimed to investigate socio-demographic differences between households having experienced a fire and those who had not.

Method Using a cross-sectional study design, a questionnaire was sent to a stratified sample $(n=20,000)$ of the Swedish population regarding if the household had experienced a fire during the past 5 years. Pearson's $\chi^{2}$-test was used to test for bivariate associations between residential fires and socio-demographic covariates, and log-binomial regression models were applied to obtain covariate-adjusted risk ratios.

Results Significant factors associated with an increased risk of residential fires were a high education level, being born outside of the Nordic countries and having children 6-12 years living at home. A significant decreased risk was observed amongst elderly and those living in rented, multi-family houses.

Discussion There seems to be a lack of agreement between determinants for fires and for fire mortality. This would indicate that the risk of fire mortality per residential fire is greatly increased for certain groups and that the increased risk of fire mortality is not due to a more common occurrence of fires.

Published in Fire Technology, May 2015, Volume 51, Issue 3, pp 615-626

\section{MEASURING THE EFFECTIVENESS OF FIRE PREVENTION}

Laine Tuomas. University of Tampere, Finland

10.1136/injuryprev-2016-042156.108

Background Evaluation of the effectiveness of public undertakings has become more and more important during the last decades. This is a major concern also in the field of fire safety. Yet, little progress has been made since the 1970's and there still is no consensus on the proper way to measure the effectiveness of fire prevention programs.

In Finland, fire prevention has for long been a notable part of the rescue service. Lately, fire department databases, data collecting processes and standards have improved, and much work has been done to collect relevant information concerning fire prevention impacts, risk variation of target groups and condition variables related to accidents. However, more tenable measures and better knowledge on the causal effects of the programs are still needed.

Methods The data consist over 350,000 observations of different fire prevention initiatives in six regions and over 800,000 buildings covered by regional fire departments between 2008 and 2014. In addition, data collected from the national accident 